\title{
Should Advertisers Avoid Controversial TV Content? Female Viewer Loyalty and Purchase Intent in the Context of Targeted Sponsorship Vignettes
}

\author{
Grzegorz Banerski ${ }^{1}$, Cezary Biele², Marcin Awdziej ${ }^{3}$, Adam Kaczyński ${ }^{4}$ Sylwester Molenda ${ }^{5}$
}

Submitted: 9.10.2020. Accepted: 26.03.2021

\section{Abstract}

Purpose: This study aims to investigate whether controversial TV content impacts the effects of non - standard advertising such as sponsorship vignette among female viewers.

Methodology: The present study used two field experiments $(n=222 ; n=219)$ conducted as a Computer-Assisted Web Interview (CAWI) questionnaire, during which video material was presented. The study manipulated controversial and non-controversial and the variable of congruence and incongruence - through the argument of video material in the form of TV programs and advertising spots.

Results: The empirical investigation revealed that controversial and incongruent content does not necessarily alter the effect of a sponsorship vignette. Loyal viewers who consistently follow programs were found to have higher purchase intent than less loyal ones.

Implications: The results suggest that advertisers should consider placing their messages in the context of controversial TV programming, which does not have to be congruent with the ads displayed.

Limitations: The stimuli applied in the studies were arbitrary, to a certain extent. The study did not investigate program's about sex that fit the definition of controversiality.

Originality/value: The study contributes to the existing literature on ad-content congruence by investigating consumer responses to innovative ad format: the sponsorship vignette. We investigated how specific content watched in longer periods of time (i.e. a series) may impact the advertising effectiveness of embedded sponsorship vignettes. This approach allowed us to demonstrate the importance of viewers' loyalty towards a TV program, resulting in a change of the level of purchase intent of advertised product.

Keywords: sponsorship vignette, loyalty, purchase intentions, controversial program, media context, congruence.

JEL: M37

\footnotetext{
1 Corresponding author, National Information Processing Institute, Laboratory of Interactive Technologies, 188B Niepodległości Ave, Warsaw 00-608, Poland, e-mail: grzegorz.banerski@opi.org.pl; https://orcid.org/0000-0002-5499-1685.

2 National Information Processing Institute, Laboratory of Interactive Technologies, 188B Niepodległości Ave, Warsaw 00-608, Poland, e-mail: cezary.biele@opi.org.pl.

3 Kozminski University, 57 Jagiellońska St, 03-301 Warsaw, Poland, e-mail: mawdziej@kozminski.edu.pl; https://orcid.org/0000-00029113-5896.

4 Kantar Polska S.A., 9 Konesera Sq., Warsaw 03-736, Poland, e-mail: adam.kaczynski@kantar.com.

5 Discovery Polska S.A., 12 Bielańska St, Warsaw 00-085, Poland, e-mail: sylwester_molenda@discovery.com.
} 


\section{Introduction}

The female television audience is of particular interest to advertisers due to their income, the length of time spent by them watching programs, and cross-category product shopping (e.g. travel electronics or home improvement) that have "traditionally" been considered mostly targeted to men. More and more frequently, broadcasters expand their selection of lifestyle programs and tailor their content to the interests of women (Consoli, 2016). Therefore, it seems necessary to investigate female viewers' reactions to advertising in such media contexts. To compete for fragmented audiences, TV networks develop more controversial programming, which is targeted at female viewers, though advertisers have concerns about placing advertisements in such contexts. This may be supported by the perception that women tend to be more sensitive to negative stimuli compared to men, which is to be partially determined biologically and psychosocially (Lungu et al., 2015). Most importantly, advertisers and advertising professionals believe that context is critical for brand placement (Phillipot and Kattukaran, 2014).

Controversial content is not a particularly new occurrence on TV, and the impact of violent or sexual programs on audiences has been studied extensively for decades (Bushman and Huesmann, 2006). However, due to intense competition for fragmented audiences, violent, sexual, and unconventional content has become even more ubiquitous (Huesemann, 2007). There are many notable examples of controversial programs that attracted large audiences, such as HBO's Game of Thrones, Dexter, or the Viacom CBS's CSI franchise.

Moreover, advertisers currently face serious problems due to growing ad avoidance, which concerns different types of media and almost all ad formats. Avoidance behaviors are induced to a large extent by viewers' previous overexposure to ads (Zanjani, Diamon, and Chan, 2011). The problem is particularly visible in the case of television, whose viewers intentionally avoid commercial breaks, and this can reduce viewership (Anderson and Gans, 2011). Other factors that influence ad avoidance include the type of program displayed, advertisement characteristics, and the network (Wilbur, 2016). In the USA, 37\% of viewers dislike advertising on TV (Ampere Analysis, 2018). The percentage of fully viewed ads fell from $97 \%$ in the early 1990 s to less than $20 \%$ in the middle of the first decade of 2000 (Teixeira, 2014). Consumers use various strategies to avoid TV ads, including ad blocking technologies. More consumers search for video content primarily online, including Video-On-Demand services (VOD), Personalized Video Recorders (PVR), and more currently, streaming platforms, on which they may select ad-free options. The use of VOD or PVR for recording live programs and fast-for- 
warding advertisements both make it more difficult for marketers to reach the consumer with their message.

In the last decade, the usefulness of television as a means for advertising has changed considerably. First, television was "dethroned" by the Internet, when the latter became the major advertising medium, attracting more advertising budgets globally since 2015 (Zenith, 2018). Online advertising spending has grown steadily at an annual growth rate of over 10\% since 2007 (IAB Polska, 2007). That said, online advertising also faces certain difficulties in reaching audiences who hold even more active control over what they watch and when by using ad blocking software. In 2017, losses due to the use of various ad blocking software were estimated at USD 409 million (PAP, 2017). Global TV audiences are now very fragmented, with viewers preferring the more specialized, targeted content of thematic channels, available due to growing channel diversity. Advertising management becomes difficult because viewers can choose to view the same content on different devices. This has all resulted in advertising losing its former impact. Nevertheless, advertisers still spend considerable budgets on large campaigns, though they now focus more on developing fewer, more effective ads and embedding them in specific contents, as this method can amplify advertising effects (Martin-Luengo, Luna, and Migueles, 2015).

Forms of TV advertising can be described in three categories:

- traditional spots aiming at reaching a wide coverage, precise targeting, and contextual advertising (i.e. 20-30-seconds-long spots transmitted in dedicated breaks);

- sponsoring that allows a brand to create a specific image and highlight the most important features of a product (e.g. monosponsoring, multisponsoring, power sponsoring);

- "non-standards" offer a variety of unique ad products that create 360 brand experience - can drive product awareness and purchase consideration (e.g. vignette, product placement, brand partnership).

In light of changes in media and TV consumption in particular, advertisers seek an alternative to traditional spots, no longer tolerated by consumers (Verhellen et al., 2015). The problem of ad avoidance can be partially solved by using different communication techniques, such as non-standard forms of advertising or their combination with other forms such as sponsorship vignettes. Sponsorship vignettes consist of five to 30 seconds of static or animated content, attached to the beginning of a TV program, indicating the program sponsor. The most commonly used format is an 
eight-second-long vignette aimed to build brand awareness and, importantly, the image of the presented product. Noteworthy, the use of sponsorship vignettes in comparison to other non-standard forms of advertising places a particularly strong emphasis on the direct link between the sponsor's brand and a specific program. One of the advantages of advertising through sponsorship vignettes is that a vignette is part of a program and, as such, appears both on TV and online video content; it cannot be avoided by viewers. However, since the relationship between an ad and a program has been traditionally perceived as a factor that can affect ad effectiveness (Barclay et al., 1965; Kennedy, 1971; Worchel et al., 1975), advertisers may be afraid of using sponsorship in programs associated with crime scenes, violence, strong language, assuming these contextual features will spoil the image of their brands and will not convey sales message properly. Sponsorship vignette is a relatively novel technique, so the scope of its use is still limited.

As advertising effects can be impacted by the type of media used and the advertising format, this study aims to investigate how the effects of this specific advertising technique are impacted by the type of programming context in which it is embedded. In this paper, we investigate how female viewer loyalty toward a TV program or series and the thematic congruence between an ad and controversial content may impact one's purchase intent. Thus far, studies of congruence between media context and ad effectiveness have resulted in mixed and inconclusive results.

Our research offers several contributions to advertising literature. First, we contribute to the existing literature on ad-content congruence by investigating consumer responses to an innovative ad format: the sponsorship vignette. To the best of our knowledge, no research is currently available on how specific content watched in longer periods of time (i.e. a series) may impact the advertising effectiveness of embedded sponsorship vignettes. Therefore, we replaced "program liking" - a common measure of viewers' attitude toward program content (Murry, Lastovicka, and Singh, 1992) - with "loyalty" to a program, as seemingly more appropriate for successively watched programs like a series. In this way, we better capture attitudes toward program content. We demonstrate the importance of viewers' loyalty towards a TV program, resulting in a change in the level of purchase intent of the advertised product. The results of the study contribute to the discussion on the impact of the controversial content of $\mathrm{TV}$ programs on embedded ads and the impact of content congruence.

The remainder of the paper is organized as follows. First, the rationale for examining ad programming congruence and controversial program content as a context for advertising is given and hypotheses are presented. Next, the study methodology is described 
in detail: questionnaire procedure and design, stimuli development, participants, and measures. This is followed by the results of two experimental studies. The paper closes with general conclusions, limitations, and future research.

\section{Theoretical Background and Hypotheses}

\section{Advertising Context and Ad Programming Congruence}

Advertising context refers to editorial factors or the programming surrounding an ad (the stimulus context) and to situational factors and conditions under which a stimulus is perceived and assessed (the viewing context; Coulter and Punj, 1999; De Pelsmacker, Geuens, and Anckaert, 2002). It can also be understood as "the characteristics of the content of the medium in which an ad is inserted" (De Pelsmacker, Geuens, and Anckaert, 2002, p. 49). Aaker and Brown (1972) define context effect as the differential impact of an advertisement when embedded in one program over the identical advertisement embedded in another.

There is substantial research into how context impacts consumer responses to advertising (De Pelsmacker, Geuens, and Anckaert, 2002), whose results reveal that advertising context triggers psychological reactions that can be transferred to ads and influence how they are processed (Myers, Royne, and Deitz, 2014). Within research on the impact of editorial or programming on attitudes toward a brand, variables such as contextual and program involvement, program-induced affect, program liking, and cognitive and affective priming were studied (Coulter and Punj, 1999; Kwon et al., 2019). Most of the studies found relatively small effects, which may be reduced by temporal distance from the content (Murry, Lastovicka, and Singh, 1992). Coulter and Punj (1999) argue that the stimulus context is therefore not present during ad viewing; its impact is relatively fleeting.

By making some needs more salient, the media can motivate viewers to pay attention to context-congruent ads (MacInnis and Jaworski, 1989; Myers, Royne, and Deitz, 2015).

Congruence indicates the general level of similarity or agreement, where concepts of relatedness, relevance, compatibility, or fit are used in more narrow contexts (Myers, Royne, and Deitz, 2014). Congruent information is better processed and perceived; it should positively impact attitudes and behaviors (Kamins and Gupta, 1994; Pracejus and Olson, 2004; Chang, 2012). The priming effect explains context effects to some degree in the case of television advertising, where viewers are exposed to stimuli from programs. These can increase the accessibility of certain knowledge structures (cogni- 
tive priming) or emotions (affective priming; Yi, 1990; Venmahavong et al., 2019) and make viewers more responsive to specific ads. Affect can be transferred from a program to a brand, resulting in more positive attitudes (Fuchs, 1964). Hence, consumers create associations between the information in the media and advertising messages (Myers, Royne, and Deitz, 2014). Studies of the effects of congruency on ad recall and attitude report mixed results.

A study by De Pelsmacker, Geuens, and Anckaert (2002) find that individuals who were highly involved with a product perceived ads embedded in contrasting context as clearer and more likable. Ads embedded in a highly appreciated TV context resulted in a more positive attitude toward the ad; ad content was also positively impacted by positively regarded media content. Advertisers generally tend to choose media content that is related thematically to their product (Martin-Luengo, Luna, and Migueles, 2015). However, research does not unequivocally confirm that choosing thematically congruent content allows for more effective advertising. For example, a study by Moorman et al. (2002) indicates that recognition is better for thematically congruent content. On the contrary, Furnham, Gunter, and Richardson (2002) find better recall for ads embedded in an incongruent context. There is no explicit answer as to whether thematic congruence affects ad recall as most of the studies are either inconclusive or identify no differences (Martin-Luengo, Luna, and Migueles, 2015).

\section{Programming Liking, Loyalty, and Negative Emotions}

An important moderator of consumers' reactions to advertising is their 'liking' of the media content in which it is embedded. Program liking is "a summary evaluation of the experience of viewing a television program” (Murry, Lastovicka, and Singh, 1992, p. 442), and researchers agree that it should be distinguished from the feelings it evokes. TV viewers respond differently to the negative feelings elicited by TV content compared to the negative feelings brought on by real-life events. This explains why people voluntarily choose to watch certain genres of content like dramas or horror films. A TV program can elicit negative feelings but still be liked. There is substantial empirical evidence that program-induced affect has an influence on ad and brand evaluations (Chang, 2011). Coulter (1998) proposes that the more viewers like a TV program, the better they rate embedded ads. Murry, Lastovicka, and Singh (1992) also demonstrate that variance in ad attitudes results from liking a TV program, regardless of the valence of the affect induced by the program itself. More favorable evaluations of ads embedded in liked programs can be explained by the spillover effect (Krugman, 1983; Shapiro, Hitch, and Tuchman, 2020). Affect toward a program works as an information (judgment) heuristic: consumers who believe they like a program are more 
likely to transfer this affect onto embedded ads. The influence of program liking is independent of the feelings it evokes. As an emotional state, liking can be very fleeting, and moderated by situational factors surrounding a particular viewing act.

Moreover, TV programs that are liked can be followed by viewers for extended periods. Series or soap operas are probably the best examples. Even if one's degree of liking differs from one episode to another, or changes from one season to the next, one has a relatively stable overall attitude to the program. In this case, the use of the concept of loyalty seems to be more appropriate. The concept of loyalty includes not only the favorability of the program but also the behavioral aspect related to its watching repeatability (Dick and Basu, 1994). In this sense, loyalty better captures attitude toward program content.

Advertisers conventionally assume that program-elicited emotions can influence TV viewers' attitudes toward ads and brands which are embedded in the content (Murry and Dacin, 1996). Some studies have confirmed that ads have been more effective when shown along with happy programs than with sad ones, as their association with experienced feelings positively impacted viewers' perceptions of the embedded ads and brands (Goldberg and Gorn, 1987; Shapiro and Macinnis, 2002; Yegiyan, 2015). Lajos, Ordabayeva, and Chattopadhayay (2012) find that under some conditions, viewers may hold more favorable attitudes toward ads embedded in sad programs than in happy ones. The relationships between content-elicited emotions, program liking, and the effectiveness of ads is not so straightforward (Murry and Dacin, 1996). Murry, Lastovicka, and Singh (1992) find that if viewers liked a specific program, then ads embedded in content eliciting negative feelings had a similar performance to those embedded in programs with a positive tone. Hence, advertisers should rather consider whether viewers have favorable attitudes toward specific programs and not the emotions the programs elicit (Murry and Dacin, 1996). According to current theories, marketers should intentionally avoid putting ads into any content that evokes negative feelings - a belief contradicted by the popularity of TV programs whose content evokes feelings of anger, fear, disgust, or sadness (Kwon et al., 2019). Murry and Dacin (1996) propose that negative emotions would not have a negative effect on program popularity if they are believed not to signal real threats to viewers' well-being. Negative emotions signal problems that require deeper and more analytical processing, hence individuals tend to analyze environmental stimuli more carefully (Weiner, 1986; Schwartz, 1990; Stavraki et al., 2021). 


\section{Controversial Content and Advertising Effects}

The term controversial content is not a precise one, as the potential controversy in media content is subjectively assessed by consumers. In the literature, three main types of content may be identified as potentially controversial: violence, sex, and themes related to death. These three broad categories share characteristics: they evoke strong and often negative feelings in viewers or contradict their worldviews. Despite common advertising wisdom that such media contexts should be avoided, some advertisers purposely place their messages around them. The main reason for that is the audience size. Among these, adults (from 18 to 34 years old) are the most difficult to attract, as their preferred medium is the Internet. Nevertheless, it is an important age group to advertisers, as they tend to have the most disposable income (Lull and Bushman, 2015) and are believed to be more easily impacted by ads than older segments with more habit-based purchasing behaviors (Hamilton, 1998). This group of viewers is also the most drawn to media content containing violence and sex (Lull and Bushman, 2015).

Selective attention to violent and sexual cues is usually explained on the grounds of evolution, suggesting that the human mind has evolved to pay closer attention to threats to safety and mating opportunities, which in turn allow for increased survival and reproductive advantages (Neuberg, Kenrick, and Schaller, 2010). Such cues are emotionally arousing, and many studies indicate that they attract attention at the expense of other less arousing stimuli in the environment (Lull and Bushman, 2015). From an advertising perspective, violent or sexual content not only attracts attention but also narrows it through the emotional arousal it generates; these are crucial steps in the processing model of advertising effectiveness (Shimp and Gresham, 1983; Poels and Dewitte, 2019) ). Violent and sexual content might demand more cognitive resources than nonviolent and nonsexual types. As attention and working memory are limited-capacity resources (Lang, 2000), attention is narrowed on cues responsible for emotional arousal, which are processed centrally, while surrounding stimuli that lead not to emotional arousal are processed peripherally and suffer from impaired attention (Christianson, 1992). A study by Bushman (2007) finds that brands advertised on television using violent content led to worse recall than brands embedded in nonviolent content. According to Reichert (2002), sexual cues are effective in attracting attention to an ad but inhibit recall of the advertised brand - a pattern that is confirmed generally by research (Sparks and Lang, 2015). However, there is an exception to the pattern of impaired brand memory, reduced brand attitudes, and lowered purchasing intentions by violent and sexual content - when ad and media content are congruent. In congruent contexts, brand cues fuse with surrounding content, resulting in difficulties with brand recall (Bryant and Zillmann, 1994). Hence, ads are more visible 
when embedded in incongruent contents. Content intensity can be also a potential moderator of advertising effectiveness (Bushman and Lull, 2015). Bushman and Lull (2015) conclude that recall is poorer when a brand is advertised in violent media, and it is evaluated less favorably, which results in lower purchase intent. With the growing intensity of content, attitudes and purchasing intent decrease, but when ads and content are congruent, recall and purchase intent improve. Fried and Johansson (2008) argue that violent content does not impair one's memory of ads but can influence a viewer's mood or cognitive involvement, which in turn may interact with the content of an ad - and inhibit recall.

Death-related media content - depicting or implying death or life-threatening situations - is pervasive on television today, yet the impact of such contexts is not well understood. The few existing studies report mixed results, with some suggesting that death-related content impacts consumers' evaluations of embedded ads (Arndt et al., 2004), and others claiming the opposite (Liu and Smeesters, 2010). The mechanisms of affective and cognitive priming that may influence consumers' ad and brand responses do not seem applicable in death-related media contexts (Lui and Smeesters, 2010).

When it comes to the female audience, women have more affective brain responses while processing negative emotions (Lungu et al., 2015). Various studies suggest that emotional content influences visual attention, leading to different information processing (Bemdall, Mohamed, and Thompson, 2019). The cognitive interference hypothesis suggests that controversial content, evoking negative feelings, may impair memory and worsen the brand attributes and purchase intentions of female viewers (Furnham, Gunter, and Walsh, 1998).

In accordance with available research on the impact of the congruent/incongruent context of embedded advertising and women's affective responses to controversial content stimuli, this study will explore how the interaction between controversial (autopsy, heroin addiction), congruent/incongruent TV content, and consumer loyalty to TV programs may influence female consumers' purchase intent. Based on the literature review, we expect that placing a sponsorship vignette in congruent/incongruent and controversial contexts will produce the following effects on female viewers:

H1: Female viewers exposed to a sponsorship vignette in an incongruent and controversial context will show lower purchase intent toward an advertised product than female viewers exposed to a sponsorship vignette in a congruent and non-controversial context. 
H2: Female viewers who are loyal to a program's content will show higher purchase intent for an advertised product than female viewers who are not loyal to that program content.

The present study tested these two hypotheses on two different product types: hedonic (Experiment 1) and utilitarian (Experiment 2). We selected these types because they have different levels of engagement and represent nearly binary categories (hedonic/ utilitarian). It is known that for these product categories the influence of emotions in advertising may be different (e.g. Geuens, Pelsmacker, and Faseur, 2011), so we may expect that they may also influence the controversial/non-controversial and congruent/ incongruent context.

\section{Research Methodology}

\section{Questionnaire Procedure and Design}

The present study used two field experiments conducted by Kantar Poland, a research agency, as a Computer-Assisted Web Interview (CAWI) questionnaire, during which video material was presented. The research agency manages a Panel owned by Discovery Polska $(N=12,160)$ that includes people who a) declare having watched lifestyle programs from the Discovery portfolio for at least one year, and b) have agreed to participate in marketing and scientific research. Discovery recruited the panelists. First, Discovery advertised the option of subscribing to the Panel on their channels on TV. Next, one could subscribe to the Panel through the Discovery Channel website. To encourage panelists to participate in surveys, each panelist who took part in the three surveys received promotional codes which they could exchange for prizes (books, CDs, pre-paid cards, etc.) in an online store.

In order to best reflect real-life viewing conditions, we were particularly interested in recruiting viewers of the TLC channel, which broadcasts popular but controversial programs. TLC is a global brand available in more than 86 million homes in the USA and 279 million other households around the world; it targets a primarily female audience (The Futon Critic, 2019). TLC is rated among the top 10 to 15 pay TV channels in many territories (Digital TV Europe, 2011). In the case of a lifestyle channel, women aged 16-49 make up 79\% of the total audience and are the core target for marketers (Nielsen Audience Measurement, 2018). Therefore, the sample in both experiments consisted only of women in this age range. 
We were especially interested in programs concerning autopsy and heroin addiction on TLC. The popular programs were perceived by advertisers interested in buying airtime on TLC as potentially too drastic to provide contexts for sponsorship vignettes. To a certain extent, the choice of the program content was arbitrary in the study. However, it was driven by real advertisers' concerns. Later, with a preliminary study, we confirmed the validity of using these programs as controversial contextual stimuli for a sponsorship vignette.

In our study, we included people aged between 16 and 18, who are also an important part of the audience for lifestyle channels. Therefore, we did not consider testing programs with sexual content that fit the definition of controversiality.

In the first step, people who met the initial selection criteria (i.e. women, aged 16-49, watching lifestyle channels including the TLC channel at least once a month) were selected from the Discovery Panel $(n=1915)$. Then, an e-mail was sent with an invitation to participate in the study. Next, the IT system randomly assigned the subjects to Experiment 1 or Experiment 2. The subjects could only participate using their laptops or PCs. It was not possible to complete the study on a mobile device. This limitation was intended to bring the conditions of the experiment closer to the natural situation of watching television. The respondents received the first reminder after seven days and the second reminder 12 days after the launch of the survey. The study was closed 14 days after its launch. At the very beginning, the efficiency of sound settings was verified. For this purpose, a random sound was played for the subjects to identify (e.g. a trumpet, a violin, drums). The IT system randomly assigned the subjects to one of three experimental conditions: the incongruent and controversial context condition, the incongruent and controversial context (condition 2), or the congruent and non-controversial context condition.

The response rate amounted to 29\% in Experiment 1 and 28\% in Experiment 2. Due to additional selection criteria included in the screener (i.e. watching certain TLC programs at least once a month), $\mathrm{n}=53$ and $\mathrm{n}=49$ subjects dropped out in Experiment 1 and Experiment 2, respectively.

In Experiment 1 and Experiment 2, the questionnaire was composed of five parts, A to E. Part A contained screening questions with the following respondent selection criteria: a) gender, b) age, c) viewership of lifestyle channels, and d) viewership of lifestyle programs on the TLC network. The next task for the respondents was to assess loyalty to individual programs, using three statements (part B). Randomization was applied to avoid ordering effects in the data set. In Part C, the subjects were randomly 
assigned to one of the three experimental conditions concerning context: a) a sponsorship vignette (praline for Experiment 1, a bank account for Experiment 2) was attached to the incongruent and controversial program 1 (heroin addiction), b) incongruent and controversial program 2 (autopsy), or c) congruent and non-controversial context (fashion in Experiment 1, a news show in Experiment 2). In Part D, respondents assessed purchase intent for the advertised product. Finally, in Part E, we measured the awareness of sponsorship vignettes, which could impact levels of purchase intent (Appeal, 1971; Cacioppo and Petty, 1989). The age (provided in Part A) and sponsorship vignette awareness were later used in our analyses as control variables.

The present study manipulated congruence and incongruence - but also the variable of controversial and non-controversial - through the argument of video material in the form of advertising spots and TV programs. The intersection of these two dimensions creates the following four scenarios: a) incongruence $x$ controversial, b) incongruence $\mathrm{x}$ non-controversial, c) congruence $\mathrm{x}$ controversial, and d) congruence $\mathrm{x}$ non-controversial. Taking into account the applied aspect of the study, we decided to include in the study only the conditions most interesting from an advertisers' viewpoint: incongruence and controversiality (a) are the rarest because of advertisers' concerns but may have untapped potential due to the large number of popular and controversial programs on lifestyle channels, while congruent and non-controversial (d) are the most sought after by the advertisers (Martin-Luengo, Luna, and Migueles, 2015). Incongruent and non-controversial (b) materials form a typical combination, so they are not interesting from the viewpoint of advertisers and the novelty of research results. On the other hand, congruent and controversial (c) combination is very rare and also not interesting to advertisers; even if such programs/products exist, their number is very small, and the practical value of the results would be small. Since the focus of this study was the effect of program content, two of the most opposing situations (a vs. d) were tested: a controversial TV program with an incongruent ad and a non-controversial TV program with a congruent ad.

\section{Stimuli Development: Context Type}

A preliminary study was carried out to evaluate the video materials for Experiment 1 and Experiment 2. We wanted to ensure that the video materials were suitable for creating a) an incongruent and controversial context, and b) a congruent and non-controversial context.

The sample $(n=60)$ was comprised of women aged $16-49$, who watched lifestyle channels at least once a week. The sample was divided into two independent groups of 
equal number. The first group watched video material intended for use in incongruent and controversial conditions:

a) a sponsorship vignette advertising praline,

b) a sponsorship vignette advertising a bank account,

c) a TV program about heroin addiction, and

d) a TV program about autopsy.

The second group watched video material intended for use in congruent and non-controversial context conditions:

a) a sponsorship vignette advertising praline,

b) a sponsorship vignette advertising a bank account,

c) a TV program about fashion, and

d) a news show.

The vignettes lasted eight seconds and each of the programs was a 2.5-minute-long fragment. First, we checked what emotions the vignettes and each of the programs evoked in both groups, respectively. The subjects answered using a five-point scale, ranging from "definitely positive” to "definitely negative." Randomization was applied to avoid ordering effects. Next, we checked both groups' perceptions of the suitability of the sponsorship vignettes in relation to the programs. At this stage, we used a visually aided question about the extent to which the advertisement (vignette) fits in with the particular program. The subjects used a five-point scale to indicate their answers, ranging from "definitely fits" to "definitely does not fit." In this task, we also applied randomization to avoid ordering effects.

For the purposes of Experiment 1, we first conducted a $t$-test, which showed that the fashion program evokes significantly more positive emotions $(M==3.43, \mathrm{SD}=1.30)$ than the ones concerning heroin addiction $(M=2.60, \mathrm{SD}=1.04) t(58)=2.74, p=.008$ and autopsy $(M=2.70, \mathrm{SD}=0.95), t(58)=2.49, p=.016$. The vignette (praline) evoked positive emotions $(M=4.33, \mathrm{SD}=0.66)$. Moreover, the $t$-test showed that the fashion program fits the sponsorship vignette (praline) better than heroin addiction $t(58)=2.91$, $p=.005$ or autopsy $t(58)=3.10, p=.003$, according to the subjects. On average, the subjects reported a better fit between the sponsorship vignette and fashion $(M=2.70$, $\mathrm{SD}=1.14)$ than between the vignette and heroin addiction $(M=1.77, \mathrm{SD}=1.00)$ or the former and autopsy $(M=1.70, \mathrm{SD}=1.02)$. 
For the purpose of Experiment 2, we first conducted a $t$-test which showed that the news show evokes significantly more positive emotions $(M=3.57$, SD $=0.78)$ than the programs on heroin addiction $(M=2.60, \mathrm{SD}=1.04), t(58)=4.09, p=.000$ and autopsy $(M=2.70, \mathrm{SD}=0.95), t(58)=3.87, p=.000$. The vignette (for a bank account) evoked positive emotions $(M=3.67, \mathrm{SD}=0.84)$. The second $t$-test showed that the news show is perceived as a significantly better fit to the sponsorship vignette (for a bank account) than the program on heroin addiction $t(58)=2.71, p=.009$ or autopsy $t(58)=2.38$, $p=.021$. On average, the subjects declared a better fit between the sponsorship vignette and news show $(M=2.70, \mathrm{SD}=1.32)$ than between the vignette and heroin addiction $(M=1.87, \mathrm{SD}=1.04)$ or the former and autopsy $(M=1.93$, $\mathrm{SD}=1.17)$.

The results of preliminary research showed that a) programs about the autopsy and heroin addiction evoked negative emotions, as opposed to the vignettes (praline, bank account) and b) were not perceived as "fitting" the vignettes. Attaching vignettes to these programs allows for the creation of incongruent and controversial contexts. The program about fashion and the news show a) evoked positive emotions and b) reportedly fit the vignettes. Thus, attaching vignettes to these programs allows one to create congruent and non-controversial contexts. The manner in which the vignette and programs were combined in Experiment 1 is shown in Figures 1a, 1b, and 1c. The combinations used in Experiment 2 were shown in Figures 2a, 2b, and 2c. The figures include frames from the video materials used.

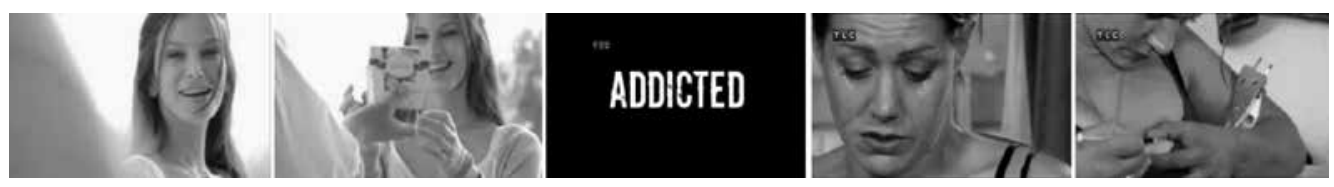

Figure 1(a). Incongruent and controversial 1: vignette (pralines) attached to heroin addiction

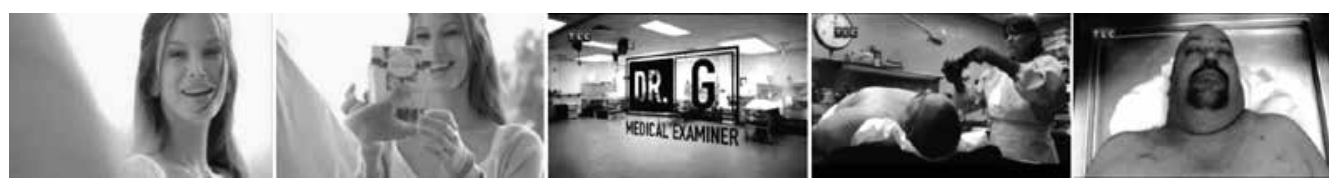

Figure 1(b). Incongruent and controversial 2: vignette (pralines) attached to autopsy
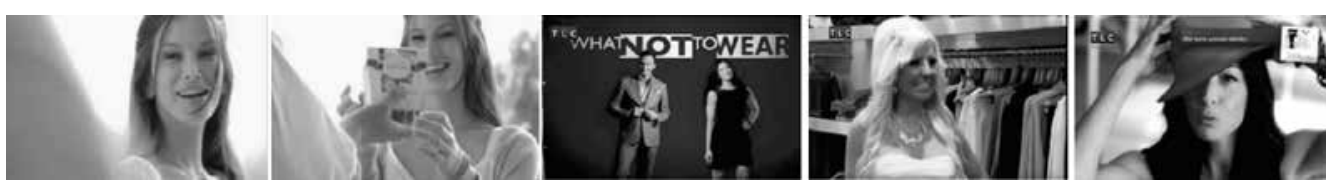

Figure 1(c). Congruent and non-controversial: vignette (pralines) attached to fashion 

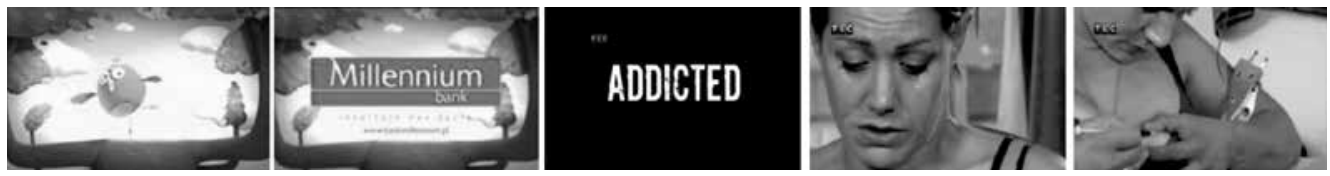

Figure 2(a). Incongruent and controversial 1: vignette (bank) attached to heroin addiction
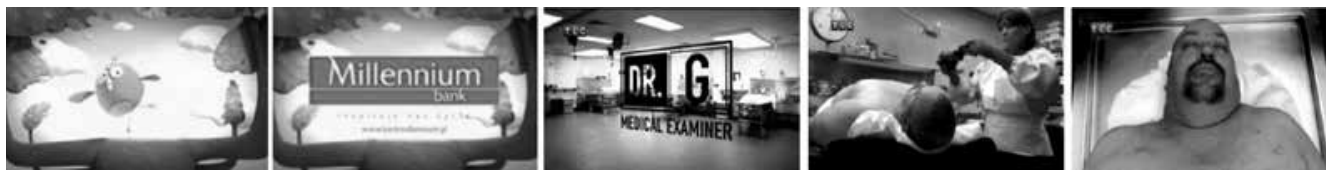

Figure 2(b). Incongruent and controversial 2: vignette (bank) attached to autopsy
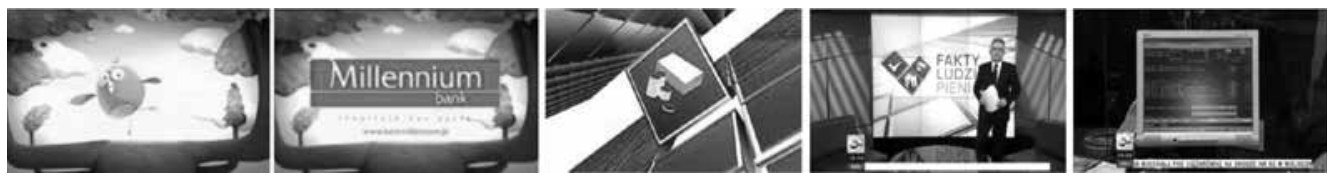

Figure 2(c). Congruent and non-controversial: vignette (bank) attached to a news show

\section{Participants}

\section{Experiment 1}

After the initial selection of Discovery Panel members, we distributed the CAWI questionnaire. Finally, subjects with the following characteristics were qualified to participate in the experiment: a) women, b) aged 16-49, c) watching lifestyle channels including TLC channel at least once a month, d) watching TLC programs including programs about autopsy, heroin addiction, and fashion at least once a month. The total sample size amounted to $n=222$. The average age was $26.22(\mathrm{SD}=6.62, \mathrm{~min} .=17$, $\max .=47)$. The participants were randomly assigned to the incongruent and controversial context condition 1 (heroin addiction) $(n=68)$, incongruent and controversial context condition 2 (autopsy) ( $n=70$ ), or congruent and non-controversial context condition (fashion) $(n=84)$.

\section{Experiment 2}

In Experiment 2, we use the same method and selection criteria as in Experiment 1, adding a criterion of watching the news on TV at least once a month. The total sample size was $n=219$. The average age was $25.85(\mathrm{SD}=6.57$, $\min .=15, \max .=49) .{ }^{6}$ The

6 The age of subjects is reported according to the Discovery Panel database. There were two respondents who declared that they were 16 years old although they were marked in the database as aged 15 years. This is due to the fact that these people were about to turn 16 . If 
subjects were randomly assigned to the incongruent and controversial context condition 1 (heroin addiction; $n=79$ ), incongruent and controversial context condition 2 (autopsy; $n=68$ ), or congruent and non-controversial context condition (news show; $n=72)$.

\section{Measures}

\section{Experiment 1}

\section{The Dependent Variable}

In Experiment 1, the dependent variable was declared purchase intent, which was measured with one question about willingness to buy the product shown in the sponsorship vignette. To answer this question, the subjects used a five-point Likert scale. Purchase intent is a reliable measure of the extent to which an ad will modify consumer behavior. According to Ajzen and Fischbein (1980), human behavior derives from attitudes. The theory of planned behavior (Ajzen, 1991) assumes that intention is the direct factor influencing human behavior. Prediction capabilities of human behavior have been confirmed in several studies (cf. Hrubens, Ajzen and Daigle, 2001; Armitage and Conner, 2001; Ajzen and Davis, 2002).

\section{Independent Variables}

The independent variables used in Experiment 1 were a) program loyalty and b) context type.

The loyalty measurement was based on a two-dimensional model of loyalty by Dick and Basu (1994), operationalized by the Walker Information company (Walker, 2002) The company has been conducting vast corporate research with a reliable metric of loyalty. Using this metric helped brands to predict customer behavior across multiple product categories and divide customers into loyal and disloyal (Walker, 2002). We employed three items to measure loyalty toward the program content. Two items referred to the attitudinal (cognitive) aspect of loyalty and one item referred to the behavioral aspect. The attitudinal aspect was connected to the degree one felt committed to the program, e.g. "It would be a problem for me if I could not watch this program." Respondents answered all three questions using a five-point Likert scale, in which 1 was the minimum and meant "strongly disagree" and 5 was the maximum and indicated "strongly agree." The average of the two statements measuring attitudinal aspects was counted for each subject. The behavioral aspect was connected to

they had answered the survey at the end of the fieldwork, they would have been 16 years old. Therefore, we decided not to remove these two cases from the study. 
the degree to which one was willing to continue watching a particular program ("In the next two weeks I will definitely watch this program”). Truly loyal viewers were characterized by their positive opinion about the program and strong willingness to watch it. ${ }^{7}$ If the score for each dimension (attitudinal and behavioral) was four or more, the subject was categorized as being truly loyal to a particular program. This procedure allowed the subjects to be qualified to two groups: "Loyal viewers" and "Disloyal viewers."

The context type included a) an incongruent and controversial context and b) a congruent and non-controversial context for the sponsorship vignette advertising praline (Rafaello). The incongruent and controversial context 1 was designed with the program about heroin addiction (Addicted). The incongruent and controversial context 2 was designed with the program about autopsy (Doctor $G$ ). The congruent and non-controversial context was designed with the program about fashion (What not to Wear).

\section{Control Variables Across Conditions}

We considered two control variables, namely age and sponsorship-vignette awareness. Subjects recorded their year of birth at the stage of completing the screening questions. Sponsorship vignette awareness was measured with the following visually aided question: "Have you seen this ad before you started this survey?" The respondents answered "Yes," coded as 1, or "No" coded as 0 . Thus, people who answered "No" were seeing the sponsorship vignette for the first time. People who answered "Yes" indicated that they saw the sponsorship vignette at least once before.

\section{Experiment 2}

\section{Dependent Variables}

As a dependent variable, we used declared purchase intent, which was measured with one question about willingness to set up a bank account as advertised in the sponsorship vignette. As in Experiment 1, to answer this question, the subjects used a fivepoint Likert scale.

\section{Independent Variables}

The same measures of loyalty toward the program content were used as in Experiment 1. Likewise, context type included a) an incongruent and controversial context and b) a congruent and non-controversial context. The incongruent and controversial

\footnotetext{
7 The period in which the repetition of activities should occurred among loyal people was adapted to the needs of this research. We arbitrarily decided that regular program viewing should take place at least once every two weeks. Usually, lifestyle programs have a premiere episode every week. Given unexpected events in viewers' lives, we decided that two weeks is the maximum period within which a loyal viewer would watch a program.
} 
contexts were designed with the same programs about heroin and autopsy but this time the programs were paired with a sponsorship vignette advertising a bank account (Millennium). The congruent and non-controversial context was designed with the news show (Facts, people, money).

\section{Control Variables Across Conditions}

The same measures of age and sponsorship-vignette awareness were used as in Experiment 1.

\section{Results}

\section{Results of Experiment 1}

To avoid potential confounding effects, a series of analyses were performed to establish whether there were any significant differences between the subject pools in different experimental conditions. We tested differences with respect to a) age and b) sponsorship-vignette awareness, for factors used in the analyses (loyalty toward a program and the context type). These results confirm that the differences between groups seen in the $t$-test and ANOVA analyses described above were not effects of age variations (Table 1) and sponsorship-vignette awareness (Table 2).

Table 1. Change in age by independent variables

\begin{tabular}{|c|c|c|c|c|c|c|c|c|}
\hline & T-test & $N$ & $M$ & $S D$ & SEM & $t$ & $d f$ & $p$ \\
\hline \multirow{3}{*}{ Loyalty } & Loyal & 95 & 25.29 & 6.51 & 0.67 & 1.82 & 220 & .07 \\
\hline & Disloyal & 127 & 26.92 & 6.65 & 0.59 & & & \\
\hline & ANOVA & $N$ & $M$ & $S D$ & SEM & $F$ & $d f$ & $p$ \\
\hline \multirow{3}{*}{$\begin{array}{l}\text { Context } \\
\text { type }\end{array}$} & $\begin{array}{l}\text { Incongruent and } \\
\text { controversial } 1\end{array}$ & 68 & 26.37 & 6.84 & 0.83 & 0.06 & 2 & .94 \\
\hline & $\begin{array}{l}\text { Incongruent and } \\
\text { controversial } 2\end{array}$ & 70 & 26.00 & 6.72 & 0.80 & & & \\
\hline & $\begin{array}{l}\text { Congruent and } \\
\text { non-controversial }\end{array}$ & 84 & 26.30 & 6.43 & 0.70 & & & \\
\hline
\end{tabular}

Source: own elaboration. 
Table 2. Change in sponsorship-vignette awareness by independent variables

\begin{tabular}{|c|c|c|c|c|c|c|c|c|}
\hline & T-test & $N$ & $M$ & $S D$ & SEM & $t$ & $d f$ & $p$ \\
\hline \multirow{3}{*}{ Loyalty } & Loyal & 95 & 0.56 & 0.83 & 0.09 & 1.30 & 220 & .19 \\
\hline & Disloyal & 127 & 0.40 & 0.92 & 0.08 & & & \\
\hline & ANOVA & $N$ & $M$ & $S D$ & SEM & $F$ & $d f$ & $p$ \\
\hline \multirow{3}{*}{$\begin{array}{l}\text { Context } \\
\text { type }\end{array}$} & $\begin{array}{l}\text { Incongruent and } \\
\text { controversial } 1\end{array}$ & 68 & 0.59 & 0.81 & 0.10 & 0.91 & 2 & .40 \\
\hline & $\begin{array}{l}\text { Incongruent and } \\
\text { controversial } 2\end{array}$ & 70 & 0.43 & 0.91 & 0.11 & & & \\
\hline & $\begin{array}{l}\text { Congruent and } \\
\text { non-controversial }\end{array}$ & 84 & 0.40 & 0.92 & 0.10 & & & \\
\hline
\end{tabular}

Source: own elaboration.

Table 3 presents statistics of statements constituting the loyalty concept, showing the assessment of the tested programs. Regardless of whether the subjects assessed controversial (heroin addiction, autopsy) or non-controversial programs (fashion), their attitudes toward these programs were favorable. Moreover, respondents declared a strong desire to watch the programs.

Table 3. Descriptive statistics of statements constituting the loyalty concept

\begin{tabular}{|c|c|c|c|c|c|}
\hline \multirow{2}{*}{$\begin{array}{l}\text { Aspects } \\
\text { of loyalty }\end{array}$} & \multirow{2}{*}{ Statements } & & $\begin{array}{l}\text { Heroin } \\
\text { addiction }\end{array}$ & Autopsy & Fashion \\
\hline & & & Controversial 1 & Controversial 2 & $\begin{array}{c}\text { Non- } \\
\text { controversial }\end{array}$ \\
\hline \multirow{4}{*}{$\begin{array}{l}\text { Attitudinal } \\
\text { aspect } \\
\text { of loyalty }\end{array}$} & \multirow{2}{*}{$\begin{array}{l}\text { I am very attached } \\
\text { to the }[\ldots . . .] \text { program }\end{array}$} & $M$ & 3.88 & 3.83 & 3.68 \\
\hline & & SD & 1.09 & 1.18 & 1.04 \\
\hline & \multirow{2}{*}{$\begin{array}{l}\text { It would be a problem } \\
\text { for me if I could not watch } \\
\text { this program }\end{array}$} & $M$ & 3.47 & 3.37 & 3.24 \\
\hline & & SD & 1.29 & 1.27 & 1.24 \\
\hline \multirow{3}{*}{$\begin{array}{l}\text { Behavioural } \\
\text { aspect } \\
\text { of loyalty }\end{array}$} & \multirow{3}{*}{$\begin{array}{l}\text { In the next two weeks } \\
\text { I will definitely watch } \\
\text { this program }\end{array}$} & $\mathrm{M}$ & 4.32 & 4.29 & 4.18 \\
\hline & & SD & 0.84 & 1.01 & 0.97 \\
\hline & & $\mathrm{N}$ & 68 & 70 & 84 \\
\hline
\end{tabular}

Source: own elaboration. 
The reported study focused on the influence of context type and loyalty toward program content on one's purchase intent, in the case of a given advertisement. In order to test the influence of the abovementioned factors, we conducted a 2x3 ANOVA analysis (Table 4). It showed the significance of the main effect of content loyalty $(F(1,210)=5.58, p=.02)$. Viewers loyal to the program content showed a higher purchase intent than disloyal viewers $(M=3.77, \mathrm{SD}=0.09$ vs. $M=3.49, \mathrm{SD}=0.08)$. No other main effects or interaction effects had statistical significance (Figure 3).

\section{Table 4. Results of $2 \times 3$ ANOVA}

\begin{tabular}{|l|c|c|c|c|c|}
\hline \multicolumn{1}{|c|}{ Source } & SS & $\boldsymbol{d f}$ & $\boldsymbol{M S}$ & $\boldsymbol{F}$ & $\boldsymbol{p}$ \\
\hline Corrected Model & $5.03^{\mathrm{a}}$ & 5 & 1.00 & 1.34 & 0.25 \\
\hline Intercept & $2,818.08$ & 1 & $2,818.08$ & $3,765.35$ & 0.00 \\
\hline Loyalty & 4.18 & 1 & 4.18 & 5.58 & 0.02 \\
\hline Type of context & 0.16 & 2 & 0.08 & 0.11 & 0.90 \\
\hline Loyalty*Type of context & 0.80 & 2 & 0.40 & 0.54 & 0.59 \\
\hline
\end{tabular}

a. R Squared $=.030$ (Adjusted R Squared $=.008$ ).

Source: own elaboration.

Figure 3. Differences in purchase intent for the advertised product

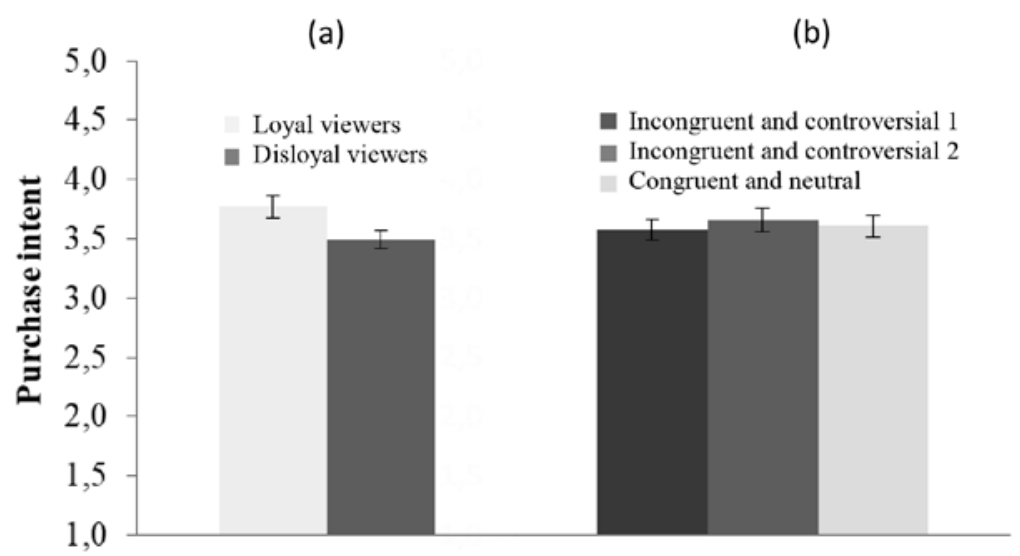

(a) Mean purchase intent of the advertised product among viewers loyal $(n=95)$ vs. disloyal $(n=127)$ toward program content.

(b) Mean purchase intent of the advertised product among viewers who see the ad in incongruent and controversial context $1(n=68)$ vs. incongruent and controversial context $2(n=70)$ vs. congruent and non-controversial context $(n=84)$.

Error bars denote standard errors around the mean.

Source: own elaboration. 
Our findings suggested that regardless of whether subjects saw the sponsorship vignette in the controversial and incongruent or a congruent and non-controversial context, they were equally eager to buy the advertised product. Thus, the context type had no significant impact on purchase intent, which rejected Hypothesis 1.

Viewers loyal to the program content showed a higher purchase intent than disloyal viewers, which confirmed Hypothesis 2.

\section{Results of Experiment 2}

The first step was, again, to verify if there was any influence from age and sponsorship vignette awareness. Regarding loyalty toward the program content and type of context, the differences between groups tested in the T-test and ANOVA analyses described above did not result from variations in age (Table 5) and sponsorship awareness (Table 6).

Table 5. Change in age by independent variables

\begin{tabular}{|c|c|c|c|c|c|c|c|c|}
\hline & T-test & $N$ & $M$ & $S D$ & SEM & $t$ & $d f$ & $p$ \\
\hline \multirow{3}{*}{ Loyalty } & Loyal & 103 & 26.09 & 7.2 & 0.71 & 0.49 & 217 & .62 \\
\hline & Disloyal & 116 & 25.65 & 5.98 & 0.56 & & & \\
\hline & ANOVA & $N$ & $M$ & $S D$ & SEM & $F$ & $d f$ & $p$ \\
\hline \multirow{3}{*}{$\begin{array}{l}\text { Context } \\
\text { type }\end{array}$} & $\begin{array}{l}\text { Incongruent and } \\
\text { controversial } 1\end{array}$ & 79 & 26.32 & 6.51 & 0.73 & 0.97 & 2 & .38 \\
\hline & $\begin{array}{l}\text { Incongruent and } \\
\text { controversial } 2\end{array}$ & 68 & 26.25 & 7.21 & 0.87 & & & \\
\hline & $\begin{array}{l}\text { Congruent and } \\
\text { non-controversial }\end{array}$ & 72 & 24.97 & 5.99 & 0.71 & & & \\
\hline
\end{tabular}

Source: own elaboration.

In Experiment 2, as in Experiment 1, subjects had favorable attitudes toward both controversial (heroin addiction, autopsy) and non-controversial programs (the news show), and they declared having a strong desire to watch these programs (Table 7). 
Table 6. Change in sponsorship-vignette awareness by independent variables

\begin{tabular}{|c|c|c|c|c|c|c|c|c|}
\hline \multicolumn{2}{|c|}{ Student's t-test } & $N$ & $M$ & $S D$ & SEM & $t$ & $d f$ & $p$ \\
\hline \multirow{3}{*}{ Loyalty } & Loyal & 103 & 0.13 & 1.00 & 0.10 & 0.56 & 217 & .58 \\
\hline & Disloyal & 116 & 0.05 & 1,00 & 0.09 & & & \\
\hline & ANOVA & $N$ & $M$ & $S D$ & SEM & $\boldsymbol{F}$ & $d f$ & $p$ \\
\hline \multirow{3}{*}{$\begin{array}{l}\text { Context } \\
\text { type }\end{array}$} & $\begin{array}{l}\text { Incongruent and } \\
\text { controversial } 1\end{array}$ & 79 & 0,06 & 1.00 & 0.12 & 0.054 & 2 & .95 \\
\hline & $\begin{array}{l}\text { Incongruent and } \\
\text { controversial } 2\end{array}$ & 68 & 0.12 & 1.00 & 0.12 & & & \\
\hline & $\begin{array}{l}\text { Congruent and } \\
\text { non-controversial }\end{array}$ & 72 & 0.08 & 1.00 & 0.07 & & & \\
\hline
\end{tabular}

Source: own elaboration.

Table 7. Descriptive statistics of statements constituting the loyalty concept

\begin{tabular}{|c|c|c|c|c|c|}
\hline \multirow{2}{*}{$\begin{array}{l}\text { Aspects } \\
\text { of loyalty }\end{array}$} & \multirow{2}{*}{ Statements } & & $\begin{array}{l}\text { Heroin } \\
\text { addiction }\end{array}$ & Autopsy & News show \\
\hline & & & Controversial 1 & Controversial 2 & $\begin{array}{c}\text { Non- } \\
\text { controversial }\end{array}$ \\
\hline \multirow{4}{*}{$\begin{array}{l}\text { Attitudinal } \\
\text { aspect } \\
\text { of loyalty }\end{array}$} & \multirow{2}{*}{$\begin{array}{l}\text { I am very attached } \\
\text { to the [...] program. }\end{array}$} & $\mathrm{M}$ & 4.07 & 3.90 & 3.74 \\
\hline & & SD & 1.00 & 0.93 & 1.16 \\
\hline & \multirow{2}{*}{$\begin{array}{l}\text { It would be a problem } \\
\text { for me if I could not } \\
\text { watch this program }\end{array}$} & $\mathrm{M}$ & 3.41 & 3.24 & 3.21 \\
\hline & & SD & 1.33 & 1.33 & 1.35 \\
\hline \multirow{2}{*}{$\begin{array}{l}\text { Behavioural } \\
\text { aspect } \\
\text { of loyalty }\end{array}$} & \multirow{2}{*}{$\begin{array}{l}\text { In the next two weeks } \\
\text { I will definitely watch } \\
\text { this program }\end{array}$} & $\mathrm{M}$ & 4.49 & 4.47 & 4.33 \\
\hline & & SD & 0.73 & 0.76 & 0.86 \\
\hline & & $\mathrm{N}$ & 79 & 68 & 72 \\
\hline
\end{tabular}

Source: own elaboration.

Experiment 2 was conducted using the same methodology as Experiment 1, but the tested sponsorship vignette advertised a different product. We conducted a similar 2x3 ANOVA analysis with context type and content loyalty as factors (Table 8). Only the main effect of content loyalty was statistically significant $(F(1,207)=7.21, p=.001)$. 
Viewers loyal to the program content showed a higher purchase intent than disloyal viewers $(M=3.19, \mathrm{SD}=0.09$ vs. $M=2.85$, $\mathrm{SD}=0.10)$. No other main effects or interaction effects reached statistical significance (Figure 4).

\section{Table 8. Results of 2x3 ANOVA}

\begin{tabular}{|l|c|c|c|c|c|}
\hline \multicolumn{1}{|c|}{ Source } & SS & $\boldsymbol{d f}$ & $\boldsymbol{M S}$ & $\boldsymbol{F}$ & $\boldsymbol{p}$ \\
\hline Corrected Model & $10.71^{\mathrm{a}}$ & 5 & 2.14 & 2.34 & 0.04 \\
\hline Intercept & 1970.20 & 1.00 & $1,970.20$ & $2,148.84$ & 0.00 \\
\hline Loyalty & 6.61 & 1.00 & 6.61 & 7.21 & 0.01 \\
\hline Type of context & 4.63 & 2.00 & 2.32 & 2.53 & 0.08 \\
\hline Loyalty*Type of context & 0.08 & 2.00 & 0.04 & 0.04 & 0.96 \\
\hline
\end{tabular}

${ }^{a} \mathrm{R}$ Squared $=.052$ (Adjusted R Squared $=.030$ )

Source: own elaboration.

Figure 4. Differences in purchase intent for the advertised product

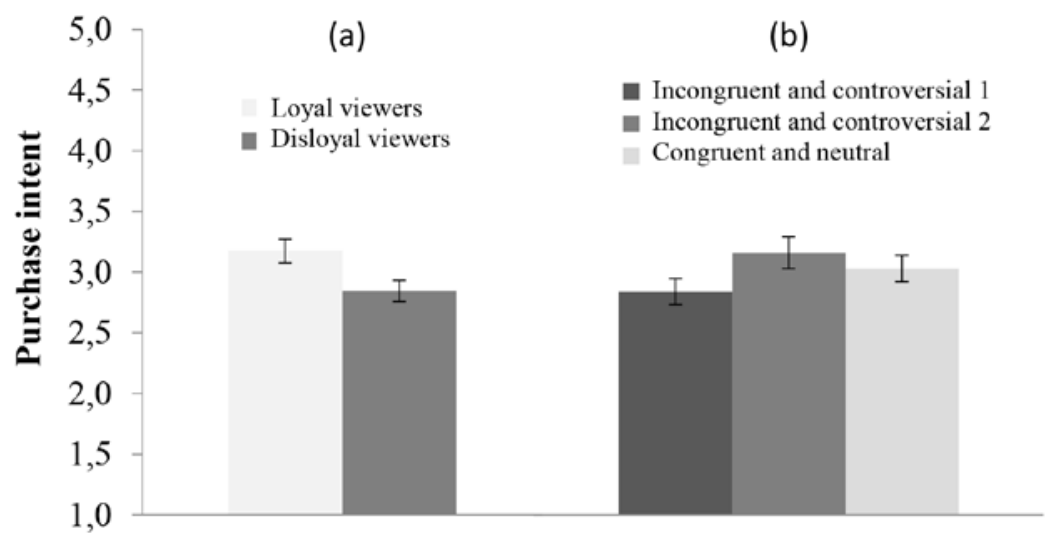

(a) Mean purchase intent of the advertised product among viewers loyal $(n=103)$ vs. disloyal $(n=116)$ toward program content.

(b) Mean purchase intent of the advertised product among viewers who see the ad in incongruent and controversial context $1(n=79)$ vs. incongruent and controversial context $2(n=68)$ vs. congruent and non-controversial context $(n=72)$.

Error bars denote standard errors around the mean.

Source: own elaboration.

In Experiment 2, as in Experiment 1, the context type had no significant impact on purchase intent, which rejected Hypothesis 1. Viewers loyal to the program content showed a higher purchase intent than disloyal viewers, which confirmed Hypothesis 2. 


\section{Discussion, Implications, Limitations, and Future Research}

The present research aimed to contribute to the literature on advertising by addressing the existing gap in knowledge as to how controversial and incongruent - but also non-controversial and congruent - content in TV programs may impact purchase intent. The subjects were female viewers who intentionally choose and repetitively watch programs that are widely recognized as controversial. Controversial program content strengthens the incongruence of a program-ad context. As part of the population that is more responsive to negative stimuli, women were recipients of controversial TV program content, which could additionally strengthen the impact of this content. We also examined the viewers' loyalty to the program content, which served as context for the ads. It allowed us to investigate to what extent being loyal to the program content impacted the purchase intent toward the advertised product.

No negative impact from controversial and incongruent context was observed on purchase intent among female viewers. Furthermore, viewers loyal to a program were more likely to buy the advertised product than disloyal viewers. We obtained the same results in both experiments in which we tested the hedonistic (Experiment 1) and utilitarian (Experiment 2) product.

Both results can be explained by viewers' positive attitudes toward the program content. Furthermore, the habituation process may play an important role. Both in Experiment 1 and Experiment 2, viewers had positive attitudes toward programs applied in incongruent and controversial contexts and were familiar with this kind of content as TLC viewers. The lack of negative impact from incongruent and controversial contexts on purchase intent seems understandable considering the loyalty toward the program content.

Overall, attitude can be defined as the product of cognitive, affective, and behavioral processes (e.g. Breckler, 1984). Attitude formation can be based on cognitive, affective, or behavioral components. In experience with an object, each component may have a different sign (favorable - positive; unfavorable - negative toward the object). During attitude formation processes, the components interact with each other, ultimately forming a positive, ambivalent, or negative overall attitude (Eagly and Chaiken, 1993). People who were attached to watching a given program (a positive cognitive process) and regularly watched it (a positive behavioral process) despite experiencing negative emotions (a negative affective process) transferred their favorable evaluation toward the program onto the advertised products. Accordingly, more loyal viewers were more likely to buy the advertised products. We obtained similar results to those of Murry, 
Lastovicka, and Singh (1992) who conclude that the direction of change in one's purchase intent toward an advertised product depends on the degree to which someone likes watching a program (program liking), and not on the emotions that this program elicits.

Second, due to the habituation process - the discrete reduction of response to repeatedly presented stimuli over time (cf. Thompson and Spencer, 1966; Wright et al., 2001) - controversial content may not have a sustained strong impact even on female viewers.

The current study provides several important implications for marketers. First, it suggests that there are additional factors - unrelated to the sponsorship vignette itself - which may increase or decrease its effectiveness, as reflected in the level of purchase intent for the advertised product. The context type was not one of them. This finding contradicts some marketers' concerns that if advertising (a sponsorship vignette) is placed in an incongruent context and even strengthened by controversial content, it will be less effective.

Our findings suggest that advertisers should not be afraid of pairing their ads or brands with controversial TV programs, provided they have a loyal female audience. Viewers' loyalty toward a program can amplify some advertising effects, regardless of its controversial nature or incongruence. Contrary to the existing convictions of advertisers and advertising professionals, the programming context may not necessarily be the key determinant of brand safety (Phillpot and Kattukaran, 2014). Among the now fragmented TV audiences, lifestyle channels with loyal viewer bases may provide advertisers with the desired scale. The results of our study in connection with earlier findings - that incongruence enhances ad recall (Furnham, Gunter, and Richardson, 2002) - suggest placing ads in incongruent and controversial context in order to effectively capture the attention of viewers without negatively impacting their purchase intent.

Channels with controversial content have viewers with particular preferences, indicating that they may be more loyal toward their TV channel and also easier to analyze according to certain expectations and behaviors. Those target groups can be defined using different criteria (e.g. content) and therefore are different than target groups defined by more mainstream models. Those target groups may offer similar commercial opportunities as target groups defined by traditional models. Channels with content preferred by this type of audience can provide a new vehicle for access to the precisely defined target groups while offering relatively lower costs of reach, resulting from preferential pricing in such program blocks. 
Therefore, the conclusion for marketers is that it may be rational to conduct an additional search for channels or program blocks with loyal viewers, even if the content presented is considered controversial. It seems that first of all, it is worth considering lifestyle and restricted channels (e.g. those showing fights or crimes), for which the fact of paying subscription fees is an indicator of their attractiveness in terms of the offered content. Such channels attract viewers with specific preferences, which in turn make them more loyal to the content. This leads to a more flexible construction of media plans for TV commercials, considering more narrowly defined target groups.

Regarding the limitations of the study, the sample consisted of female viewers (16-49 years of age.), as women are the target audience base for lifestyle TV channels. The age criterion of the respondents caused an additional restriction. We did not test programs with sexual content, which is an important part of the category of controversiality.

Certain restrictions in the research stemmed from its practical focus. Both studies were conducted with women as the basis of a modest set of context types, which restricts the potential generalization of findings to a larger number of product categories or to other market populations. In order to collect answers, we used materials (sponsorship vignettes, programs) that had been broadcast on TLC previously, meaning that some viewers (study participants) may have seen the content which they had viewed before, which could have affected their emotional responses. Repeated viewing of the same content is not considered unusual behavior in the context of this study.

Furthermore, the stimuli applied in the studies were arbitrary, to a certain extent. First, the choice of the program content was driven by real advertisers' concerns. The programs were potentially perceived to be too drastic to provide contexts for sponsorship vignettes. Second, although the stimuli used to create a congruent condition fit the sponsorship vignette better than in the incongruent condition - that fit occurred to a moderate degree. Perhaps the impact of the context on purchase intent would have been revealed, had the stimulus been highly fitted to the vignette in a congruent condition. However, by using pieces of actual programming in the study, we used what we considered to be the best match.

In the future, it would be advisable to add products from other categories, to increase the generalizability of results (such as FMCG vs. long-life consumer goods), or the degree of involvement (high vs. low) might affect the abovementioned congruency relationships. Moreover, the types of content and sponsorship could make a difference 
(context). The effectiveness of sponsorship vignettes that evoke different feelings (such as joy, sadness, anger, or fear) could be tested in different contexts (e.g. positive vs. neutral, neutral vs. negative, or congruent vs. incongruent).

Undoubtedly, future research is needed in the field of programs about sex that fit the definition of controversiality. Programs included in this category differ significantly from one another, ranging from soft erotic programs (e.g. Playboy) to hard porn combined with violence (e.g. Bang Battle: the winner in an MMA fight has sex in the cage). The perception of the spot may vary in the context of erotic content with different intensity, especially between men and women who perceive this content differently (Lull and Bushman 2015; Samson, 2018).

Finally, future research should include other media in order to investigate the degree to which the above relationships are media-type sensitive. As video content moves from the linear broadcast era through over-the-top content (OTT) and moves toward the so-called Walled Garden Era, content is becoming increasingly adapted to individual needs (Malthouse, Maslowska, and Franks, 2018). Formerly passive media consumers are now playing a more active role; they can state their preferences and receive content tailored to their needs. Over-the-top providers (e.g. Netflix, HBO GO, YouTube, Amazon) offer large libraries with search options and recommendations based on viewers' previous choices. It remains to be investigated whether vignettes can be applied to OTT as a form of advertising and paired with more controversial content.

\section{References}

Aaker, D. and Brown, P. (1972). Evaluating Vehicle Source Effects, Journal of Advertising Research, $12,11-16$.

Ajzen, I. (1991). The theory of planned behavior. Organizational Behavior and Human Decision Processes, 50, 179-211. https://doi.org/10.1016/0749-5978(91)90020-T.

Ajzen, I. and Fishbein, M. (1980). Understanding Attitudes and Predicting Social Behavior. Englewood Cliffs, NJ: Prentice-Hall.

Ajzen, I. and Davis, E.L. (2002). The Decision of African American Students to Complete High School: An Application of the Theory of Planned Behavior. Journal of Educational Psychology, 94(4), 810-819. https://doi.org/10.1037//0022-0663.94.4.810.

Ampere Analysis (2018). TV Advertising attitudes and Impact on Services.

https:/www.marketingcharts.com/charts/us-attitudes-tv-advertising-impact-tv-service-choice/ attachment/ampereanalysis-tv-ad-attitudes-and-impact-on-service-nov2018 (accessed: 20.03.2019).

Anderson, S.P. and Gans, J.S. (2011). Platform Siphoning: Ad-Avoidance and Media Content. American Economic Journal: Microeconomics, 3(4), 1-34. https://doi.org/10.1257/mic.3.4.1. 
Appel, V. (1971). On Advertising Wear-out. Journal of Advertising Research, 11(February), 11-13.

Armitage, C.J. and Conner, M. (2001). Efficacy of the theory of planned behaviour: A metaanalytic review. British Journal of Social Psychology, 40, 471-475. https://doi.org/10.1348/014466601164939.

Arndt, J., Solomon, S., Kasser, T., and Sheldon, K.M. (2004). The Urge to Splurge: A Terror Management Account of Materialism and Consumer Behavior. Journal of Consumer Psychology, 14, 198-212. https://doi.org/10.1207/s15327663jcp1403_2.

Barclay, W.D., Doub, R.M. and McMurtrey, L.T. (1965). Recall of TV Commercials by Time and Program Slot. Journal of Advertising Research, 5(2), 61-67. https://doi.org/10.1080/00221300009598592.

Bemdall, R.C.A., Mohamed, A., and Thompson, C. (2019). Emotional real-world scenes impact visual search. Cognitive Processing, 20, 309-316. https://doi.org/10.1007/s10339-018-0898-x.

Breckler, S.J. (1984). Empirical validation of affect, behavior, and cognition as distinct component of attitude. Journal of Personality and Social Psychology, 47, 1191-1205. https://doi.org/10.1037//0022-3514.47.6.1191.

Bryant, J. and Zillmann, D. (1994). Media effects: Advances in theory and research. Hillsdale, NJ: Erlbaum.

Bushman, B.J. (2007). That was a great commercial, but what were they selling? Effects of violence and sex on memory for products in television commercials. Journal of Applied Social Psychology, 37, 1784-1796. https://doi.org/10.1111/j.1559-1816.2007.00237.x.

Bushman, B.J. and Huesmann, L.R. (2006). Short-term and Long-term Effects of Violent Media on Aggression in Children and Adults. Arch Pediatr Adolesc Med., 160(4), 348-352. https://doi.org/10.1001/archpedi.160.4.348.

Cacioppo, J.T. and Petty, R.E. (1989). Effects off Message Repetition on Argument Processing Recall and Persuasion. Basic and Applied Social Psychology, 10(1), 3-12.

https://doi.org/10.1207/s15324834basp1001_2.

Chang, C. (2011). The Influence of Editorial Liking and Editorial-Induced Affect on Evaluations of Subsequent Ads. Journal of Advertising, 40(3), 43-58. https://doi.org/10.2753/JOA0091-3367400304.

Chang, C. (2012). Is that website for me? Website-self-congruency effects triggered by visual designs. International Journal of Advertising, 31(4), 835-860. https://doi.org/10.2501/IJA-31-4-835-860.

Christianson, S.-A. (1992). Emotional stress and eyewitness memory: A critical review. Psychological Bulletin, 112, 284-309. https://doi.org/10.1037/0033-2909.112.2.284.

Consoli, J. (2016). Women's Cable Networks Prep for Upfront Battles.

https://www.broadcastingcable.com/news/womens-cable-networks-prep-upfront-battles-114096 (accessed: 4.02.2019).

Coulter, K.S. (1998). The effects of affective responses to media context on advertising evaluations. Journal of Advertising, 27(4), 41-51. https://doi.org/10.1080/00913367.1998.10673568.

Coulter, K.S. and Punj, G. (1999). Influence of viewing context on the determinants of attitude toward the ad and the brand. Journal of Business Research, 45, 47-58. https://doi.org/10.1016/S0148-2963(98)00027-7.

De Pelsmacker, P., Geuens, M., and Anckaert, P. (2002). Media Context and Advertising Effectiveness: The Role of Context Appreciation and Context/Ad Similarity. Journal of Advertising, 31(2), 49-61. https://doi.org/10.1080/00913367.2002.10673666.

Dick, A.S. and Basu, K. (1994). Customer Loyalty: Toward an Integrated Conceptual Framework. Journal of the Academy of Marketing Science, 22, 99-113.

https://doi.org/10.1177/0092070394222001. 
Digital Tv Europe (2011). Lifestyle visions - channels targeting the female audience.

https://www.digitaltveurope.com/longread/lifestyle-visions-channels-targeting-the-female-audience/ (accessed: 4.02.2019).

Eagly, H.A. and Chaiken, S. (1993). Psychology of attitudes. TomsonWadsworth.

Fried, C., and Johanson, J. (2008). Sexual and violent media's inhibition of Advertisement memory. Effect or Artifact? Journal of Applied Social Psychology, 38, 1716-1735. https://doi.org/10.1111/j.1559-1816.2008.00366.x.

Fuchs, D.A. (1964) Two source effects in magazine advertising. Journal of Marketing Research, 1(3), 59-62. https://doi.org/10.1177/002224376400100309.

Furnham, A., Gunter, B., and Richardson, F. (2002). Effects of product- program congruity and viewer involvement on memory for televised advertisements. Journal of Applied Social Psychology, 32, 124-141. https://doi.org/10.1111/j.1559-1816.2002.tb01423.x.

Furnham, A., Gunter, B. and Walsh, D. (1998). Effects of programme context on memory of humorous television commercials. Applied Cognitive Psychology, 12, 555-567. https://doi.org/10.1002/(SICI)1099-0720(1998120)12:6<555::AID-ACP537>3.0.CO;2-X.

Geuens, M., De Pelsmacker, P., and Faseur, T. (2011). Emotional advertising: Revisiting the role of product category. Journal of Business Research, 64(4), 418-426. https://doi.org/10.1016/j.jbusres.2010.03.001.

Goldberg, M.E. and Gorn, G.J. (1987). Happy and Sad TV Programs: How They Affect Reactions to Commercials. Journal of Consumer Research, 14, 387-403. https://doi.org/10.1086/209122.

Hamilton, J.T. (1998). Channeling violence: The economic market for violent television programming. Princeton, NJ: Princeton University Press.

Hrubens, D., Ajzen, I., and Daigle, J. (2001). Predicting Hunting Intentions and Behavior: An Application of the Theory of Planned Behavior. Leisure Sciences, 23, 165-178. https://doi.org/10.1080/014904001316896855.

Huesemann, L.R. (2007). The Impact of Electronic Media Violence: Scientific Theory and Research. Journal of Adolescent Health, 41(6), 6-13. https://doi.org/10.1016/j.jadohealth.2007.09.005.

IAB Polska (2017). PwC AdEx. https://iabadex.pl/index.php (accessed: 29.03.2019).

Kamins M.A. and Gupta, K. (1994) Congruence between spokesperson and product type: a matchup hypothesis perspective. Psychology \& Marketing, 11(6), 569-586. https://doi.org/10.1002/mar.4220110605.

Kennedy, J.R. (1971). How Program Environment Affects TV Commercials. Journal of Advertising Research, 11(1), 33-38.

Krugman, Herbert E. (1983). Television Program Interest and Commercial Interruption. Journal of Advertising Research, 23(1), 21-23.

Kwon, E.S., King, K., W. Nyilasy, G., Reid, L.N. (2019). Impact of Media Context on Advertising Memory. A Meta-Analysis of Advertising Effectiveness. Journal of Advertising Research, March, 99-128. https://doi.org/10.2501/JAR-2018-016.

Lajos, J., Ordabayeva, N., and Chattopadhyay, A. (2011). Mood Matching: the Importance of Fit Between Moods Elicited By Tv Programs and Commercials. In: Z. Yi, Xiao, J.J. Cotte, and L. Price (eds.), Asia-Pacific Advances in Consumer Research, 9, 257-258. Duluth MN: Association for Consumer Research.

Lang, A. (2000). The limited capacity model of mediated message processing. Journal of Communication, 50, 46-70. https://doi.org/10.1111/j.1460-2466.2000.tb02833.x. 
Liu, J. and Smeesters, D. (2010). Have You Seen the News Today? The Effect of Death-Related Media Contexts on Brand Preferences. Journal of Marketing Research, 47(2), 251-62. https://doi.org/10.1509/jmkr.47.2.251.

Lull, R. and Bushman, B.J. (2015). Do Sex and Violence Sell? A Meta-Analytic Review of the Effects of Sexual and Violent Media and Ad Content on Memory, Attitudes, and Buying Intentions, Psychological Bulletin, 141(5), 1022-1048. https://doi.org/10.1037/bul0000018.

Lungu, O., Potvin, S., Tikàszad A. and Mendrek, A. (2015). Sex differences in effective fronto-limbic connectivity during negative emotion processing. Psychoneuroendocrinology, 62, 180-188. https://doi.org/10.1016/j.psyneuen.2015.08.012.

MacInnis, D.T. and Jaworski, B.J. (1989). Information Processing from Advertisements: Toward and Integrative Framework. Journal of Marketing, 53, 1-23. https://doi.org/10.1177/002224298905300401.

Malthouse, E.C., Maslowska, E., and Franks, J.U. (2018). Understanding programmatic TV advertising. International Journal of Advertising, 37(5), 769-784.

https://doi.org/10.1080/02650487.2018.1461733.

Martin-Luengo, B., Luna, K., and Migueles, M. (2015). Effects of Interest, Thematic Congruence, and Typicality on Memory for Television, Radio, and Press Advertisements of New Products. Applied Cognitive Psychology, 29, 560- 572. https://doi.org/10.1002/acp.3139.

Moorman, M., Neijens, P.C. and Smit, E.G. (2002). The effects of magazine-induced psychological responses and thematic congruence on memory and attitude toward the ad in a real-life setting. Journal of Advertising, 31, 27-40. https://doi.org/10.1080/00913367.2002.10673683

Murry, J.P. and Dacin, P.A. (1996). Cognitive moderators of negative-emotion effects: Implications for understanding media context. Journal of Consumer Research, 22(4), 439-447. https://doi.org/10.1086/209460.

Murry, J.P., Lastovicka, J.L. and Singh, S. (1992). Feeling and Liking Responses to Television Programs: An examination of two explanations for Media-Context Effects. Journal of Consumer Research, 18, 441-451. https://doi.org/10.1086/209272.

Myers, S., Royne, M.B., and Deitz, G. (2015). Programme-ad congruence. International Journal of Advertising, 33(1), 61-90. https://doi.org/10.2501/IJA-33-1-061-090.

Neuberg, S.L., Kenrick, D.T. and Schaller, M. (2010). Evolutionary social psychology. In: S.T. Fiske, D.T. Gilbert and G. Lindzey (eds.), Handbook of social psychology (5th ed., pp. 761-796). New York, NY: Wiley. https://doi.org/10.1002/9780470561119.socpsy002021.

Nielsen Audience Measurement (2018).

http://www.agbnielsen.pl/?document = 708\&page = /Podreczniki,spot,Arianna,TeleMonitor,TeleSpot,406.html (accessed: 20.03.2019).

PAP (2017). Internauci w Polsce blokuja reklamy. Reklamodawcy stracili 409 mln dolarów, https://www.tvp.info/33587228/internauci-w-polsce-blokuja-reklamy-reklamodawcy-stracili409-mln-dolarow?captcha_key = \#! (accessed: 29.03.2019).

Philpott, G. and Kattukaran A. (2014). Evolution of TV: 7 Dynamics Transforming TV. https://www.thinkwithgoogle.com/marketing-strategies/video/evolution-of-tv-7-dynamics-transforming-tv/ (accessed: 15.10.2020).

Poels. K. and Dewitte, S. (2019). The Role of Emotions in Advertising: A Call to Action, Journal of Advertising, 48(1), 81-90, https://doi.org/10.1080/00913367.2019.1579688.

Reichert, T. (2002). Sex in advertising research: A review of content, effects, and functions of sexual information in consumer advertising. Annual Review of Sex Research, 13, 241-273.

Samson, L. (2018). The effectiveness of using sexual appeals in advertising. Journal of Media Psychology, 30, 184-195. https://doi.org/10.1027/1864-1105/a000194. 
Schwarz, N. (1990). Feelings as information: Informational and motivational functions of affective states. In: E.T. Higgins and R.M. Sorrentino (eds.), Handbook of motivation and cognition: Foundations of social behavior, Vol. 2 (pp. 527-561). The Guilford Press.

Shapiro, B., Hitsch, G.J., and Tuchman, A. (2020). Generalizable and Robust TV Advertising Effects. NBER Working Paper, No. w27684. https://doi.org/10.3386/w27684.

Shapiro, S., and MacInnis, D.J. (2002). Understanding Program-Induced Mood Effects: Decoupling Arousal from Valence. Journal of Advertising, 31(4), 15-26. https://doi.org/10.1080/00913367.2002.10673682

Shimp, T.A. and Gresham, L.G. (1983). An information processing perspective on recent advertising literature. Current Issues and Research in Advertising, 6, 39-75.

Sparks, J.V., and Lang, A. (2015). Mechanisms underlying the effects of sexy and humorous content in advertisements. Communication Monographs, 82, 134-162. https://doi.org/10.1080/03637751.2014.976236.

Stavraki, M., Lamprinakos, G., Brinol, P., Petty, R.E., Karantinou, K., and Diaz, D. (2021). The influence of emotions on information processing and persuasion: A differential appraisals perspective. Journal of Experimental Social Psychology, 93. https://doi.org/10.1016/j.jesp.2020.104085.

The Futon Critic (2019). Ratings, http://www.thefutoncritic.com/ratings/2019/08/05/tlc-ranks-number-1-in-primetime-for-womenin-july-298201/20190805tlc01/ (accessed: 4.02.2019).

Thompson, R.F. and Spencer, W.A. (1966). Habituation: A model phenomenon for the study of neuronal substrates of behavior. Psychological Review, 73, 16-43. https://doi.org/10.1037/h0022681.

Venmahavong, T., Yoon, S., Kacy, K. and Chan, Y.Y. (2019). Five Seconds to the Ad: How Program-Induced Mood Affects Ad Countdown Effects. Journal of Advertising, 48(2), 232-241. https://doi.org/10.1080/00913367.2019.1597786.

Verhellen, Y., Eelen, J., Dens, N. and De Pelsmacker, P. (2015). The short- and long-term impact of brand placement in an advertiser-funded TV program on viewers' attitudes toward the sponsor brand and its main competitor. International Journal of Advertising. https://doi.org/10.1080/02650487.2015.1087089.

Walker (2002). "Online article”, The Walker loyalty matrix. Available at: https://www.walkerinfo. com/docs/WP-The-Walker-Loyalty-Matrix.pdf (accessed: 22.08.2018).

Weiner, B. (1986). Attribution, Emotion, and Action. In: R.M. Sorrentino and E.T. Higgins (eds.), Handbook of Motivation and Cognition (pp. 281-312). New York: Guilford.

Wilbur, K.C. (2016). Advertising Content and Television Advertising Avoidance. Journal of Media Economics, 29(2), 51-72. https://doi.org/10.1080/08997764.2016.1170022.

Worchel, S., Andreoli, V., and Eason, J. (1975). Is the Medium the Message. Journal of Applied Social, 5(2), 157-172. https://doi.org/10.1111/j.1559-1816.1975.tb01305.x.

Yegiyan, N.S. (2015). Explicating the Emotion the Emotion Spillover Effect. At the Intersection of Motivational Activation, Resource Allocation, and Consolidation. Journal of Media Psychology, 27, 134-145. https://doi.org/10.1027/1864-1105/a000164.

Yi, Y. (1991). The Influence of Contextual Priming on Advertising Effects. In: R.H. Holman, and M.R. Solomon (eds.), NA-Advances in Consumer Research. Provo, UT: Association for Consumer Research. 